\title{
Predictors of Mortality in Geriatric Patients with Upper Gastrointestinal Bleeding
}

\author{
(1) Emine Emektar ${ }^{1}$, (1) Seda Dağar ${ }^{1}$, (1) Șeref Kerem Çorbacıoğlu ${ }^{1}$, (1) Hüseyin Uzunosmanoğlu ${ }^{1}$, (1) Metin Uzman², \\ (1) Rabia Handan Karaatlı1 ${ }^{1}$ (1) Yunsur Çevik ${ }^{1}$ \\ ${ }^{1}$ Clinic of Emergency, University of Health Sciences Turkey, Ankara Keçiören Training and Research Hospital, Ankara, Turkey \\ ${ }^{2}$ Clinic of Gastroenterology, University of Health Sciences Turkey, Ankara Keçiören Training and Research Hospital, Ankara, Turkey
}

\begin{abstract}
Aim: Acute upper gastrointestinal (UGI) bleeding is a common gastrointestinal emergency and a cause of morbidity and mortality among the elderly. We aimed to evaluate the demographic and epidemiological characteristics of geriatric patients diagnosed with UGI bleeding in an emergency department (ED) to determine the predictors of 28-day mortality among them.

Materials and Methods: All patients aged $\geq 65$ years admitted to ED and diagnosed with UGI bleeding were included in this retrospective study. Baseline demographic and clinical/endoscopic findings were evaluated. The primary outcome was 28-day mortality rate and its predictors, which among geriatric patients diagnosed with UGI bleeding in an ED.

Results: In total, 297 geriatric patients were included in the study; of them, 131 were women (44.1\%). The median patient age was 79 (65-98) years. During endoscopy, the most common cause of bleeding was a gastric/duodenal ulcer (53.9\% patients). A comparison of the patient characteristics in terms of in-hospital mortality (survivor/non-survivor) revealed significant differences in chronic renal failure; hemodynamic instability; hematocrit values; blood urea nitrogen, creatinine, and albumin levels; erythrocyte transfusion; rebleeding; and Rockall scores (for all variables, $\mathrm{p}<0.05$ ). The regression analysis revealed that low albumin levels and hematocrit values as well as hemodynamic instability were the independent predictors of mortality.

Conclusion: Peptic ulcer bleeding is the main cause of acute UGI bleeding. Low albumin levels and hematocrit values as well as hemodynamic instability are the independent predictors of mortality. We believe that geriatric patients with UGI, particularly those with hemodynamic compromise at the time of hospital admission, should be closely monitored and promptly treated.
\end{abstract}

Keywords: Geriatric, upper gastrointestinal bleeding, mortality

\section{Introduction}

Because people in the twenty-first century are living longer worldwide, health problems that affect older population have been increasing (1). Additionally, the widespread usage of certain medications like anticoagulants and non-steroidal drugs (NSAIDs) has steeply increased the incidence of gastrointestinal (GI) bleeding among the older peoples $(2,3)$. Acute upper gastrointestinal (UGI) bleeding in geriatric patients that occurs most frequently over 60 years of age is a life-threatening emergency that requires rapid evaluation and appropriate management (4-8). Although the use of endoscopic homeostasis and advancements in diagnostic and therapeutic modalities have improved clinical outcomes, Gl bleeding remains an important clinical problem for geriatric patients because of their longer hospital stays and higher mortality and morbidity rates compared to those of younger patients $(2,9)$. For patients suffering from Gl bleeding, the mortality rate corresponds with increased age. Patients older than 70 years of age have a 20-30 times greater incidence of GI bleeding than patients younger than 30 years $(9,10)$. Moreover, mortality rates are $12-25 \%$ for patients older than 60 years and below $10 \%$ for patients younger than 60 years (11). This increases the importance of UGI bleeding in the geriatric population. 
Identifying predictors of mortality in geriatric patients with GI bleeding may aid in the early recognition of high-risk patients. High-risk patients frequently require hospitalization, early resuscitation, close monitoring, and urgent endoscopic interventions, whereas low-risk patients may be discharged early in the course or managed on an outpatient basis, reducing emergency department (ED) costs and crowding $(12,13)$.

In this study, we aimed to evaluate demographic and epidemiological properties to identify predictors of 28-day mortality among geriatric patients diagnosed with UGI bleeding in an ED.

\section{Materials and Methods}

\section{Design and Setting}

Our retrospective study was conducted in a tertiary care ED with approximately 250,000 patient admissions per year. Prior to implementation, our study's protocol was approved by the local ethics committee (decision no: 1792, date: 28/11/2018). As this is a retrospective study, the participants' informed consent was not required.

\section{Study Population}

All patients aged $\geq 65$ years, admitted to the ED between January 1, 2015 and January 1, 2018, diagnosed with UGI bleeding, and investigated with endoscopic examination were enrolled in this study.

Patients' comorbidities, vital signs, hospital outcomes, laboratory results, endoscopic findings, demographic characteristics, and blood product replacements were obtained from the hospital automation system and their personal medical records. Patients with missing data were excluded.

Forrest classification was used as the endoscopic bleeding index, and Forrest $1 \mathrm{a}$ and $1 \mathrm{~b}$ bleeding indicate active bleeding. Patients with a systolic blood pressure below $100 \mathrm{mmHg}$ and a heart rate over 100/min at the time of ED admission were considered to have hemodynamic instability.

The primary outcome was the identification of a 28-day mortality rate and its mortality predictors, which included all causes of mortality that occurred within 28 days of hospitalization. Mortality data were obtained from the hospital automation system and the death certificate system.

\section{Statistical Analysis}

Data analysis was performed using SPSS for Windows 16 . The normality of the distribution of the discrete and continuous variables was checked using the Kolmogorov-Smirnov test. Descriptive statistics included numbers and percentages for qualitative variables and medians (minimum-maximum) for discrete and continuous variables. Categoric variables were compared using the chi-square test, and continuous variables with the Mann-Whitney $\mathrm{U}$ test. Predictors of in-hospital mortality were determined using univariate tests, and statistically significant $(\boldsymbol{p}<0.2)$ variables were tested with a multivariate logistic regression model. The fitness of this model was tested with the Hosmer-Lemeshow test. A p value $<0.05$ was considered to be statistically significant.

\section{Results}

We enrolled 319 patients during the study period. Of these 319 patients, 22 patients were excluded due to missing data. In total, 297 patients were included in the final statistical analysis. The median age of the patients was 79 years (65-98), and 131 patients were women (44.1\%).

The most common comorbidity was hypertension ( $n=147,49.5 \%$ ). The 28-day mortality rate was $14.1 \%(n=42)$. The most common causes of death were multiorgan failure $(n=12,28.5 \%)$, sepsis $(n=9,21.5 \%)$., and acute renal failure $(n=9,21.5 \%)$.The mean time from admission to death was 11 days (0 day-28 days). Patient demographics and laboratory results are shown in Table 1.

The endoscopic findings, Forest classifications, and endoscopic interventions are summarized in Table 2. The most common bleeding etiologies were gastric and duodenal ulcers $(n=160$, $53.9 \%$ ). Active bleeding was present in $20.5 \%$ of patients $(n=61)$, and 56 of these patients (18.8\%) underwent sclerotherapy. Five patients $(1.7 \%)$ could not receive sclerotherapy because they could not tolerate the procedure and/or had their vital signs deteriorate during endoscopy. One patient underwent subtotal gastrectomy. The Rockall scores of the patients were calculated and divided into three risk groups (Table 3). 21.5\% of the patients $(n=64)$ were in the mild group, while $48.8 \%(n=145)$ were in the high-risk group. Re-bleeding was detected in seven patients (2.4\%). Four patients were treated with sclerotherapy, and three patients could not tolerate the procedure of endoscopy and sclerotherapy.

A comparison of the in-hospital mortality factors for the patients (survivors/non-survivors) revealed significant differences related to chronic renal failure, hemodynamic instability, hematocrit, blood urea nitrogen (BUN), creatinine, albumin, erythrocyte suspension transfusion, re-bleeding, and Rockall score $(p=0.007$, $p<0.001, \quad p<0.001, \quad p<0.001, \quad p=0.005, \quad p<0.001, \quad p=0.014$, $p<0.001, p<0.001$, respectively; Table 4).

Univariate regression analysis was performed to investigate the mortality variables (Table 5). Next, a multivariate Iogistic 


\begin{tabular}{|c|c|}
\hline All patients, $\mathbf{n}(\%)$ & $297(\%)$ \\
\hline Female, $\mathbf{n}(\%)$ & $131(44.1 \%)$ \\
\hline Age, years, median (minimum-maximum) & $79(65-98)$ \\
\hline \multicolumn{2}{|l|}{${ }^{*}$ Comorbidity, n (\%) } \\
\hline Hypertension & $147(49.5 \%)$ \\
\hline Diabetes mellitus & $80(26.9 \%)$ \\
\hline Coronary heart disease & $75(25.3 \%)$ \\
\hline Chronic heart failure & $32(10.8 \%)$ \\
\hline Chronic renal failure & $39(13.1 \%)$ \\
\hline Liver disease & $25(8.4 \%)$ \\
\hline Other & $32(10.8 \%)$ \\
\hline NSAID drugs use $n(\%)$ & $103(34.7 \%)$ \\
\hline Oral anticoagulant drugs use $\mathrm{n}(\%)$ & $70(23.6 \%)$ \\
\hline \multicolumn{2}{|l|}{ Presenting symptoms, n (\%) } \\
\hline Hematemesis & $160(53.9 \%)$ \\
\hline Melena & $100(33.7 \%)$ \\
\hline Syncope & $9(3 \%)$ \\
\hline Others & $28(9.4 \%)$ \\
\hline \multicolumn{2}{|l|}{ Hemodynamic status (\%) } \\
\hline Unstable & 109 (36.7\%) \\
\hline Stable & $188(63.3 \%)$ \\
\hline Rockall score, median (minimum-maximum) & $4(1-10)$ \\
\hline \multicolumn{2}{|l|}{ Laboratory results, median (minimum-maximum) } \\
\hline Hematocrit \% & $31(10-57)$ \\
\hline Platelet $\times 10^{3} / \mu \mathrm{L}$ & $253.75(32-910)$ \\
\hline BUN mg/dL & $32(6-324)$ \\
\hline Creatinine $\mathrm{mg} / \mathrm{dL}$ & $1.1(0.5-9,6)$ \\
\hline AST U/L & $18.5(16-363)$ \\
\hline ALT U/L & $13(12-264)$ \\
\hline Albumin $\mathrm{g} / \mathrm{dL}$ & $3.4(1.38-6.30)$ \\
\hline \multicolumn{2}{|l|}{ Replacement of blood products, $n(\%)$} \\
\hline Erythrocyte suspension & $132(44.4 \%)$ \\
\hline Unit, median (minimum-maximum) & $2(1-11)$ \\
\hline Re-bleeding, n (\%) & $7(2.4 \%)$ \\
\hline $\begin{array}{l}\text { Hospital stay duration median (minimum- } \\
\text { maximum) }\end{array}$ & $4(2-32)$ \\
\hline 28-day mortality n (\%) & $42(14.1 \%)$ \\
\hline \multicolumn{2}{|l|}{ Causes of death, $\mathbf{n}(\%)$} \\
\hline Multiorgan failure & $12(28.5 \%)$ \\
\hline Sepsis & $9(21.5 \%)$ \\
\hline Acute renal failure & $9(21.5 \%)$ \\
\hline Acute coronary syndromes & $8(19 \%)$ \\
\hline Others & $4(9.5 \%)$ \\
\hline \multicolumn{2}{|c|}{$\begin{array}{l}\text { NSAID: Non-steroidal anti-inflammatory drug, ALT: Alanine amino transferase, AST } \\
\text { Aspartate transaminase, BUN: Blood urea nitrogen, n: Number } \\
\text { *Some patients had multiple comorbid diseases }\end{array}$} \\
\hline
\end{tabular}

Table 2. The endoscopic findings, Forest classification and endoscopic interventions

\begin{tabular}{|l|l|}
\hline Endoscopic diagnoses & $\mathbf{n}(\%)$ \\
\hline Gastric/duodenal ulcer & $160(53.9 \%)$ \\
\hline Gastric erosion/gastritis & $131(44.1 \%)$ \\
\hline Cancer stomach & $32(10.8 \%)$ \\
\hline Esophageal varices & $18(6.1 \%)$ \\
\hline Dieulafoy's lesion & $5(1.7 \%)$ \\
\hline Mallory-Weiss tear & $5(1.7 \%)$ \\
\hline Forrest classification for gastric/duodenal ulcer & \multicolumn{2}{|l|}{} \\
\hline 1a & $3(1.8 \%)$ \\
\hline 1b & $29(18.1 \%)$ \\
\hline 2a & $12(7.5 \%)$ \\
\hline 2b & $34(21.3 \%)$ \\
\hline 2c & $32(20 \%)$ \\
\hline 3 & $50(31.3 \%)$ \\
\hline Active bleeding & $61(20.5 \%)$ \\
\hline Endoscopic intervention & $44(14.8 \%)$ \\
\hline Sclerotherapy & $6(2 \%)$ \\
\hline Hemoclip + sclerotherapy & $6(2 \%)$ \\
\hline Endoscopic band ligation & \multicolumn{2}{|l|}{} \\
\hline n: Number & \\
\hline Some patients presented with more than 1 endoscopic finding \\
\hline
\end{tabular}

Table 3. Rockall score stratification into three groups with percentage of re-bleeding and mortality of patients

\begin{tabular}{|l|l|l|l|}
\hline \multicolumn{2}{|c|}{ Group } & Re-bleeding (\%) & Mortality (\%) \\
\hline Low risk & $64(21.5 \%)$ & $0(0 \%)$ & $0(0 \%)$ \\
\hline Moderate risk & $88(29.6 \%)$ & $0(0 \%)$ & $8(9.1 \%)$ \\
\hline High risk & $145(48.8 \%)$ & $7(4.8 \%)$ & $34(23.4 \%)$ \\
\hline
\end{tabular}

regression analysis was conducted. Because BUN and creatinine levels correlate with albumin, Rockall score correlates with hypotension, and ES replacement correlates with hematocrit levels, these properties were not included in the model. The multivariate model included chronic renal failure, syncope, hemodynamic instability, hematocrit, albumin, rebleeding, age, and sex (Table 5), which had a $p$ value $<0.2$. The model was found to be fit using the Hosmer-Lemeshow test. Low albumin and hematocrit levels as well as hemodynamic instability at the time of admission were found to have adverse effects on mortality (Table 6).

\section{Discussion}

The present study which we investigated the characteristics of geriatric patients with UGI bleeding and the factors that affected their 28-day mortality provided two important results. First, 


\begin{tabular}{|c|c|c|c|}
\hline & Survivor $(n=255)$ & Dead $(n=42)$ & $p$ \\
\hline Age & 79 (65-98) & $79.4(67-96)$ & 0.581 \\
\hline \multicolumn{4}{|l|}{ Gender, n (\%) } \\
\hline Female & $111(66.3 \%)$ & $20(47.6 \%)$ & \multirow{2}{*}{0.621} \\
\hline Male & $144(56.5 \%)$ & $22(52.4 \%)$ & \\
\hline \multicolumn{4}{|l|}{ Comorbidity } \\
\hline Hypertension & $124(48.6 \%)$ & $23(54.8 \%)$ & 0.461 \\
\hline Diabetes mellitus & $67(26.3 \%)$ & $13(31 \%)$ & 0.527 \\
\hline $\begin{array}{l}\text { Coronary heart } \\
\text { disease }\end{array}$ & $67(26.3 \%)$ & $8(19 \%)$ & 0.318 \\
\hline $\begin{array}{l}\text { Chronic renal } \\
\text { failure }\end{array}$ & $28(11 \%)$ & $4(26.2 \%)$ & 0.007 \\
\hline Liver disease & $21(8.2 \%)$ & $4(9.5 \%)$ & 0.765 \\
\hline \multicolumn{4}{|l|}{ Drugs, n (\%) } \\
\hline NSAID & $90(35.3 \%)$ & $13(31 \%)$ & 0.584 \\
\hline Oral anticoagulant & $61(23.9 \%)$ & $9(21.4 \%)$ & 0.724 \\
\hline $\begin{array}{l}\text { Hemodynamic } \\
\text { Instability, n (\%) }\end{array}$ & $72(28.2 \%)$ & $37(88.1 \%)$ & $<0.001$ \\
\hline $\begin{array}{l}\text { Rockall score, } \\
\text { median (minimum- } \\
\text { maximum) }\end{array}$ & $4(1-10)$ & $6(3-10)$ & $<0.001$ \\
\hline \multicolumn{4}{|c|}{ Presenting symptoms, $\mathbf{n}(\%)$} \\
\hline Hematemesis & $137(53.7 \%)$ & $23(54.8 \%)$ & 0.901 \\
\hline Melena & $88(34.5 \%)$ & $12(28.6 \%)$ & 0.450 \\
\hline Syncope & $6(2.4 \%)$ & $3(7.1 \%)$ & 0.093 \\
\hline \multicolumn{4}{|c|}{ Endoscopic diagnosis, $\mathbf{n}(\%)$} \\
\hline $\begin{array}{l}\text { Gastric/duodenal } \\
\text { ulcer }\end{array}$ & $139(54.5 \%)$ & $21(50 \%)$ & \multirow{5}{*}{$>0.05$} \\
\hline $\begin{array}{l}\text { Gastric erosion/ } \\
\text { gastritis }\end{array}$ & $111(43.5 \%)$ & $20(47.6 \%)$ & \\
\hline Esophageal varices & $14(5.5 \%)$ & $4(9.5 \%)$ & \\
\hline Dieulafoy's lesion & $5(2 \%)$ & $0(0 \%)$ & \\
\hline Mallory-Weiss tear & $5(2 \%)$ & $0(0 \%)$ & \\
\hline \multicolumn{4}{|c|}{ Laboratory results, median (minimum-maximum) } \\
\hline Hematocrit \% & $32(10-57)$ & $26.75(15.7-42)$ & $<0.001$ \\
\hline Platelet $\times 10^{3} / \mu \mathrm{L}$ & $245(32-910)$ & $250(55-507)$ & 0.562 \\
\hline BUN mg/dL & $30(6-324)$ & $44(13-125)$ & $<0.001$ \\
\hline Creatinine mg/dL & $1.03(0.5-9.6)$ & $1.42(0.5-6.5)$ & 0.005 \\
\hline AST U/L & $18(6-363)$ & $19.5(10-154)$ & 0.507 \\
\hline ALT U/L & $13(3-264)$ & $13(6-217)$ & 0.954 \\
\hline Albumin g/dL & $3.45(1.38-6.30)$ & $3(1.8-4)$ & $<0.001$ \\
\hline $\begin{array}{l}\text { Active bleeding in } \\
\text { endoscopy, } \mathrm{n}(\%)\end{array}$ & $50(19.6 \%)$ & $11(26.2 \%)$ & 0.328 \\
\hline $\begin{array}{l}\text { Endoscopic } \\
\text { intervention }\end{array}$ & $45(15 \%)$ & $11(26.2 \%)$ & 0.679 \\
\hline Re-bleeding & $1(0.4 \%)$ & $6(14.3 \%)$ & $<0.001$ \\
\hline $\begin{array}{l}\text { Replacement of } \\
\text { blood products, } \\
\mathrm{n}(\%) \\
\text { Erythrocyte } \\
\text { suspension }\end{array}$ & $106(41.6 \%)$ & $26(61.9 \%)$ & 0.014 \\
\hline $\begin{array}{l}\text { Unit, median } \\
\text { (minimum- } \\
\text { maximum) }\end{array}$ & $2(1-11)$ & $2(1-9)$ & 0.361 \\
\hline
\end{tabular}

Table 5. Univariate analysis of factors associated with 28-day mortality

\begin{tabular}{|l|l|l|l|}
\hline & $\mathbf{p}$ value & 0dds ratio & $\mathbf{( 9 5 \% ~ C l s )}$ \\
\hline Age & 0.574 & 1.01 & $0.9-1.05$ \\
\hline Gender & 0.621 & 0.84 & $0.4-1.6$ \\
\hline Chronic renal failure & 0.009 & 2.87 & $1.3-6.3$ \\
\hline Syncope & 0.111 & 3.19 & $0.7-13.2$ \\
\hline Hemodynamic instability & $<0.001$ & 18.8 & $7.1-49.7$ \\
\hline Albumin & $<0.001$ & 0.24 & $0.12-0.4$ \\
\hline Hematocrit & $<0.001$ & 0.92 & $0.8-0.9$ \\
\hline Rockall scores & $<0.001$ & 1.55 & $1.3-1.85$ \\
\hline Erythrocyte suspension & 0.016 & 2.28 & $1.1-4.4$ \\
\hline Re-bleeding & $<0.001$ & 42.32 & $4.9-361.8$ \\
\hline Cl: Confidence interval & & & \\
\hline
\end{tabular}

Table 6. Multivariate regression model to predict in 28-day mortality

\begin{tabular}{|l|l|l|l|}
\hline & $\mathbf{p}$ value & $\begin{array}{l}\text { Odds } \\
\text { ratio }\end{array}$ & $\mathbf{( 9 5 \% \text { Cls } )}$ \\
\hline Age & 0.82 & 0.99 & $0.9-1.06$ \\
\hline Gender & 0.092 & 0.42 & $0.1-1.1$ \\
\hline Chronic renal failure & 0.297 & 1.84 & $0.5-5.7$ \\
\hline Syncope & 0.139 & 4.97 & $0.5-41.8$ \\
\hline Hemodynamic instability & $<0.001$ & 26.2 & $6.1-111.4$ \\
\hline Albumin & 0.003 & 0.26 & $0.1-0.6$ \\
\hline Hematocrit & 0.015 & 1.11 & $1.02-1.2$ \\
\hline Re-bleeding & 0.088 & 12.47 & $0.68-225.6$ \\
\hline Cl: Confidence interval & & & \\
\hline
\end{tabular}

we determined that the most common cause of Gl bleeding was peptic ulcer, which had a 28 -day mortality rate of $14 \%$. We revealed that the deceased patients were more hemodynamically unstable, had lower hematocrit and albumin levels, had higher BUN and creatinine levels, and had greater needs for blood product transfusions. Second, we demonstrated that the most important predictors of in-hospital mortality for geriatric patients with GI bleeding were hemodynamic instability at the time of ED admission and low albumin and hematocrit levels.

The increased incidence of UGI bleeding in the older population has been linked to various causes, such as increased NSAIDs usage, Helicobacter pylori incidence, and gastroesophageal reflux disease $(14,15)$. Kawaguchi et al. (3) evaluated nonvariceal UGI bleeding in the geriatric patients. They found that $41 \%$ of their patients were using NSAIDs and 34\% were using anticoagulants, and they determined that these rates were higher in geriatric patients than in patients under 65 years of age. According to our results, $34.7 \%$ of the patients were using NSAIDs and $23.6 \%$ 
were using anticoagulants. A systematic review indicated that the relative risk of GI bleeding was 2.7-33.9 for NSAIDs users (16). Notably, NSAIDs use in the geriatric patients is often overlooked. In addition to a greater prevalence of rheumatologic disorders in the geriatric population, many patients from developing countries, where medication regulation is inadequate, use these drugs without prescriptions or adequate oversight. NSAIDs users also frequently take one or more antiplatelet agents to combat cardiac or cerebrovascular comorbidities. A metaanalysis reported that taking low-dose aspirin increases the risk of UGI bleeding (17). This risk is even more pronounced among patients with a history of GI bleeding, extended aspirin usage, or simultaneous clopidogrel or anticoagulant usage (17). In the older patients, the risk of developing ulcers is increased due to their frequent NSAID and anticoagulant usage. The most common etiology of UGI bleeding in the geriatric population is peptic ulcer disease (4). In the geriatric patients, hospital admissions due to peptic ulcer disease, along with esophagitis and gastritis, comprise of $70-91 \%$ of all admissions due to UGI bleeding (18). In previous studies, the prevalence of UGI bleeding ranges from 5-43\% for stomach/duodenum ulcers, $6-42 \%$ for gastritis, and $1-20 \%$ for esophageal varices $(16,17,19)$. Similar to literature, our endoscopic findings also revealed gastric or duodenal ulcer at a rate of $53.9 \%$. Our rate for esophageal variceal bleeding was $6.1 \%$. The rate of UGI bleeding episodes due to esophageal varices is around $10 \%$ in the previous studies (12). Chronic liver diseases and their associated $\mathrm{Gl}$ complications are less common in Turkey than in other countries, and this may have contributed to the low rate of esophageal varices in our study.

Rockall scoring considers age, comorbid diseases, presence of shock, and endoscopic findings, and it is the most widely used GI bleeding scoring system $(7,13)$. In our study, $21.5 \%$ of the patients were in the mild group, while $48.8 \%$ were in the high-risk group. The Rockall scores were lower for the survivors than the nonsurvivors, and this difference was statistically significant.

Previous studies have reported in-hospital mortality rates ranging from $8.7-11.2 \%$ for geriatric patients $(4,20)$. Mortality rates are affected by the cause of the bleeding and the presence of comorbidities. Our mortality rate was $14.3 \%$. Our relatively high mortality rate may be related to our greater comorbidity rate and the extreme age of our study population. Similar to previous studies, we found low re-bleeding rates. Although these prior studies on geriatric patients with GI bleeding have linked increased mortality with the coexistence of coronary artery disease, we could not detect any significant differences (10). Chronic renal disorders were more common among deceased patients. Hence, we identified higher BUN and creatinine levels in our deceased patients. In addition, our deceased patients had lower hematocrit levels at the time of ED admission and needed more blood product transfusions.

Recent studies on Gl bleeding in the older people report heterogeneous findings on the predictors of in-hospital mortality. A study reported that high age, being hypotensive at admission, failure to achieve endoscopic hemostasis, and the presence of comorbidities, particularly liver cirrhosis associated with other comorbidities, were independent predictors of mortality (18). However, we did not find any difference in liver disease status between survivors and non-survivors. Cirrhosis is associated with many potential complications, notably the development of portal hypertension. Portal hypertension with the production of ascites, hepatic and gastric varices bleeding in the upper part of the $\mathrm{Gl}$ tract is associated with a considerably worse prognosis and an increased risk of mortality (21). This risk may be reduced by using modern pharmacotherapeutic agents and therapeutic endoscopic methods (e.g., esophageal stents and transjugular intrahepatic portosystemic shunt) to treat acute bleeding in cirrhosis patients who have experienced GIS bleeding.

Thongbai et al. (13) associated hemodynamic instability, bright red bleeding upon nasogastric aspiration, creatinine $<1.5 \mathrm{mg} / \mathrm{dL}$, and, crucially, coexisting coronary artery disease with mortality (10). In contrast, our study found that admission hemodynamic instability and low albumin and hematocrit levels negatively affected our patients' survival rates. Among patients with UGI bleeding, admission hemoglobin and hematocrit levels are critical for determining prognosis and managing treatment (22). A low admission hematocrit should inform an emergency specialist about the severity of the bleeding and the presence of active bleeding. Prior studies have reported that the serum albumin level has an important role in the prognosis of patients with GI bleeding $(23,24)$. González-González et al. (25) recently argued that the albumin level was the sole independent predictor of mortality. They showed that it had a negative predictive value as high as $97 \%$ for geriatric patients with a serum albumin level below $2.35 \mathrm{~g} / \mathrm{dL}$, and they reported that it was quite effective for discriminating between survivors and non-survivors (25). We assert that being hypotensive at the time of ED admission is a strong predictor of mortality. The hemodynamic status of geriatric patients who are initially hypotensive may suddenly deteriorate and require aggressive therapy. Therefore, care should be taken to rapidly stabilize their hemodynamic status, begin pharmacological treatment, and schedule endoscopy.

\section{Study Limitations}

Our study has some limitations. As a single-center study, its findings cannot be generalized to other centers. Notably, since our study was retrospective and some patients were referred, 
patient information such as smoking status, alcohol and drug usage, and treatment management could not be obtained. Moreover, there were five patients who could not undergo endoscopic treatment due to various reasons and we could not include to regression analysis. This situation may have affected the mortality of patients.

\section{Conclusion}

As conclusion, in the present study, hemodynamic instability, low hematocrit levels, and low albumin levels were independent predictors of mortality. It is possible to stabilize geriatric patients and prevent mortality by diagnosing high-risk patients and applying appropriate therapies. To improve outcomes, such patients should be closely monitored, resuscitative procedures should be rapidly initiated, and endoscopic interventions should be performed as soon as possible.

\section{Ethics}

Ethics Committee Approval: Prior to implementation, this study's protocol was approved by Ankara Keçiören Training and Research Hospital Ethics Committee (decision no: 1792, date: 28/11/2018).

Informed Consent: As this is a retrospective study, the participants' informed consent was not required.

Peer-review: Externally peer-reviewed.

\section{Authorship Contributions}

Concept: E.E., S.D., S.K.C.., Design: E.E., S.D., Y.Ç., Data Collection or Processing: E.E., H.U., M.U., R.H.K., Analysis or Interpretation: E.E., S.K.C.., Y.C.., Literature Search: H.U., M.U., R.H.K., Writing: E.E., S.D.

Conflict of Interest: No conflict of interest was declared by the authors.

Financial Disclosure: The authors declared that this study received no financial support.

\section{References}

1. Kalkan Ç, Soykan I, Karakaya F, Tüzün A, Gençtürk ZB. Comparison of three scoring systems for risk stratification in elderly patients with acute upper gastrointestinal bleeding.Geriatr Gerontol Int. 2017; 17:575-83.

2. Alkhatib AA, Elkhatib FA. Acute upper gastrointestinal bleeding among early and late elderly patients. Dig Dis Sci. 2010;55:3007-9.

3. Kawaguchi K, Kurumi H, Takeda Y, Yashima K, Isomoto H. Management for nonvariceal upper gastrointestinal bleeding in elderly patients: the experience of a tertiary university hospital. Ann Transl Med. 2017;5:181.

4. Elsebaey MA, Elashry H, Elbedewy TA, Elhadidy AA, Esheba NE, Ezat S, et al. Predictors of in-hospital mortality in a cohort of elderly Egyptian patients with acute upper gastrointestinal bleeding.Medicine (Baltimore). 2018;97:e0403.
5. Doğan NÖ, Akıncı E, Gümüs H, Akıllı NB, Aksel G. Predictors of inhospital mortality in geriatric patients presenting to the emergency department with ischemic stroke. Clin Appl Thromb Hemost. 2016;22:280-4.

6. Wang CY, Qin J, Wang J, Sun CY, Cao T, Zhu DD. Rockall score in predicting outcomes of elderly patients with acute upper gastrointestinal bleeding. World J Gastroenterol. 2013:19:3466-72.

7. Rockall TA, Logan RF, Devlin HB, Northfield TC. Incidence of and mortality from acute upper gastrointestinal haemorrhage in the United Kingdom. Steering Committee and members of the National Audit of Acute Upper Gastrointestinal Haemorrhage. BMJ. 1995;311:222-6.

8. Laine L, Yang H, Chang SC, Datto C. Trends for incidence of hospitalization and death due to $\mathrm{Gl}$ complications in the United States from 2001 to 2009. Am J Gastroenterol 2012;107:1190-5; quiz 1196

9. Gostout CJ. Gastrointestinal bleeding in the elderly patient. Am J Gastroenterol. 2000;95:590-5.

10. Pilotto A, Ferrucci L, Scarcelli C, Niro V, Di Mario F, Seripa D, et al. Usefulness of the comprehensive geriatric assessment in older patients with upper gastrointestinal bleeding: a two-year follow-up study. Dig Dis. 2007;25:124-8.

11. Farrell JJ, Friedman LS. Gastrointestinal bleeding in the elderly. Gastroenterol Clin North Am. 2001;30:377-407.

12. Mahajan P, Chandail VS. Etiological and endoscopic profile of middle aged and elderly patients with upper gastrointestinal bleeding in a tertiary care hospital in North India: a retrospective analysis. J Midlife Health. 2017;8:137-41.

13. Thongbai T, Thanapirom K, Ridtitid W, Rerknimitr R, Thungsuk R, Noophun P, et al. Factors predicting mortality of elderly patients with acute upper gastrointestinal bleeding. Asian Biomedicine. 2016;10:115-22.

14. Thomopoulos KC, Vagenas KA, Vagianos CE, Margaritis VG, Blikas AP, Katsakoulis $E C$, et al. Changes in aetiology and clinical outcome of acute upper gastrointestinal bleeding during the last 15 years. Eur J Gastroenterol Hepatol. 2004;16:177-82.

15. van Leerdam ME, Vreeburg EM, Rauws EA, Geraedts AAM, Tijssen JGP, Reitsma JB, et al. Acute upper GI bleeding: Did anything change? Time trend analysis of incidence and outcome of acute upper Gl bleeding between 1993/1994 and 2000. Am Gastroenterol. 2003;98:1494-9

16. Lau JY, Sung J, Hill C, Henderson C, Howden CW, Metz DC. Systematic review of the epidemiology of complicated peptic ulcer disease: incidence, recurrence, risk factors and mortality. Digestion. 2011;84:102-13.

17. Lanas A, Wu P, Medin J, Mills EJ. Low doses of acetylsalicylic acid increase risk of gastrointestinal bleeding in a meta-analysis. Clin Gastroenterol Hepatol. 2011;9:762-8.e6

18. Charatcharoenwitthaya P, Pausawasdi N, Laosanguaneak N, Bubthamala J, Tanwandee T, Leelakusolvong S. Characteristics and outcomes of acute upper gastrointestinal bleeding after therapeutic endoscopy in the elderly. World I Gastroenterol. 2011;28;17:3724-32

19. Tariq SH, Mekhjian G. Gastrointestinal bleeding in older adults. Clin Geriatr Med 2007;23:769-84

20. Lei Gu, Fei Xu, Jie Yuan. Comparison of AIMS65, Glasgow-Blatchford and Rockal scoring approaches in predicting the risk of in-hospital death among emergency hospitalized patients with upper gastrointestinal bleeding: a retrospective observational study in Nanjing, China. BMC Gastroenterol. 2018;18:98.

21. Hejda V. Late complications of liver cirrhosis - management of gastrointestinal bleeding in the presence of portal hypertension. Vnitr Lek. 2016;62:10-7.

22. Villanueva C, Colomo A, Bosch A, Concepción M, Hernandez-Gea V, Aracil C, et al. Transfusion strategies for acute upper gastrointestinal bleeding. N Engl J Med. 2013;368:11-21.

23. Tung CF, Chow WK, Chang CS, Peng YC, Hu WH. The prevalence and significance of hypoalbuminemia in non-variceal upper gastrointestinal bleeding. Hepatogastroenterology. 2007;54:1153-6.

24. González-González JA, Vázquez-Elizondo G, García-Compeán D, Gaytán-Torres J0 Flores-Rendón AR, Jáquez-Quintana J0, et al. Predictors of in-hospital mortality in patients with non-variceal uppergastrointestinal bleeding. Rev EspEnferm Dig. 2011;103:196-203

25. González-González JA, Monreal-Robles R, García-Compean D, Paz-Delgadillo J, WahSuárez M, Maldonado-Garza HJ. Nonvariceal upper gastrointestinal bleeding in elderly people: Clinical outcomes and prognostic factors. J Dig Dis. 2017;18:212-21. 